\title{
An Exploratory Study of Athletic Training Student Communication
}

W. David Carr

Missouri State University

Jennifer L. Volberding

Ben Timson

Follow this and additional works at: https://bearworks.missouristate.edu/articles-chhs

\section{Recommended Citation}

Carr, W. David, Jennifer L. Volberding, and Ben Timson. "An exploratory study of athletic training student communication." Athletic Training Education Journal 11, no. 4 (2016): 219-226.

This article or document was made available through BearWorks, the institutional repository of Missouri State University. The work contained in it may be protected by copyright and require permission of the copyright holder for reuse or redistribution.

For more information, please contact BearWorks@library.missouristate.edu. 


\title{
An Exploratory Study of Athletic Training Student Communication
}

\author{
W. David Carr, PhD, ATC*; Jennifer L. Volberding, PhD, ATC†; Ben Timson, PhD \\ *Sports Medicine \& Athletic Training, Missouri State University, Springfield; $†$ Health and Human \\ Performance, Oklahoma State University, Stillwater; $\ddagger$ Kinesiology, Texas Christian University, Fort \\ Worth
}

Context: Employers have reported that the ability to communicate is the greatest deficiency of new athletic training graduates. New graduates must be able to communicate effectively with a wide range of stakeholders to ensure the best health care of their patients. To date there have been no studies to determine which stakeholders the students are communicating with during clinical experiences.

Objective: To investigate the opportunity to communicate with various stakeholders by students during their clinical experiences.

Patients or Other Participants: Participants were 932 students (308 male, 624 female) from university athletic training programs.

Data Collection and Analysis: The study used an online survey instrument that allowed students to recall which stakeholders they had the opportunity to communicate with during the prior week of their clinical experiences. Basic descriptive statistics were calculated to describe the study sample and a $\chi^{2}$ contingency table analysis was used to determine significance. The dependent variables were stakeholders with whom they communicated (coach/clinic director, athlete/patient, parent, administrator, peer/colleague, and other health care professional) and the independent variables were demographics (sex, athletic affiliation of host institution, state/private affiliation of host institution, entry-level degree, year in program, clinical rotation setting, and athletic affiliation of clinical rotation).

Results: Year in program indicated a significant correlation with all of the dependent variables, with Cramer $V$ ranging from 0.098 to 0.157 . The highest significant correlation was found between clinical rotation setting and communication with parents (Cramer $\mathrm{V}=0.418$ ).

Conclusions: As one would expect, as students matriculate and gain higher levels of maturity, they report more opportunities to communicate. Similarly, students in multisport secondary schools or lower-level collegiate clinical experiences report more opportunities to communicate.

Key Words: Professional socialization, student interaction, clinical experience

Dr Carr is currently Assistant Professor in Sports Medicine \& Athletic Training at Missouri State University. Please address correspondence to W. David Carr, PhD, ATC, Sports Medicine \& Athletic Training, Missouri State University, 901 South National, PROF 160, Springfield, MO 65897. wdavidcarr@missouristate.edu.

\section{Full Citation:}

Carr WD, Volberding JL, Timson B. An exploratory study of athletic training student communication. Athl Train Educ J. 2016;11(4):219_ 226. 


\title{
An Exploratory Study of Athletic Training Student Communication
}

\author{
W. David Carr, PhD, ATC; Jennifer L. Volberding, PhD, ATC; Ben Timson, PhD
}

\section{INTRODUCTION}

The ability to communicate effectively is a skill that is often overlooked during a student's education but is crucial to success upon graduation. Our previous work has illustrated that employers and new employees agree that communication skills are lacking in new graduates. ${ }^{1}$ Massie et $\mathrm{al}^{2}$ found that employers felt interpersonal skills were lacking in new graduates. Many factors, such as confidence and experience, contribute to the ability to effectively communicate. ${ }^{3}$ Learning any skill requires deliberative effort and feedback, and lecturebased discussion alone cannot teach a student how to properly communicate with an injured patient. ${ }^{4}$ According to Ericsson et $\mathrm{al}^{4}$ and Ericsson, ${ }^{5}$ the student must observe, practice, receive feedback, increase responsibility, and be carefully mentored in order to develop any skill.

The field of medicine has shown that communication skills are central to quality patient care. Studies have demonstrated that clinician-patient communication has a positive impact on important health outcomes, including patient satisfaction and adherence to treatment plans. ${ }^{6-9}$ Conversely, Hickson et al ${ }^{10}$ found that patients' most frequent complaints are that clinicians do not listen to their concerns, care about their problems, or provide enough information about treatment plans. Stewart ${ }^{11}$ conducted a literature review to examine physician-patient communication and health outcomes. Stew$\operatorname{art}^{11}$ found that increased quality of communication in both the history-taking segment and the discussion of the management plan improved health outcomes such as emotional health, symptom resolution, and function.

Assessment of communication skills in medicine has focused on direct observation of clinician-patient interactions, interviews or surveys with patients, and direct outcome measures such as patient satisfaction ratings. ${ }^{12-14}$ Stein and Kwan ${ }^{13}$ conducted a study to determine the effectiveness of a 1-day communication skills intervention course for practicing physicians. Their sample of convenience found improvement in self-reported perceptions of communication skills but did not have any control group. ${ }^{13}$ Brown et al ${ }^{14}$ conducted a randomized, controlled trial studying a communication skills training program and its effect on patient satisfaction. Brown et $\mathrm{al}^{14}$ found that although the clinicians self-reported a moderate increase in communication skills, patient satisfaction scores did not improve.

Some of the literature ${ }^{15-17}$ available in athletic training has focused on clinician communication skills with regards to psychological interventions with patients while other studies $^{18-20}$ have focused on perceived supportive clinical instructor characteristics, which include effective communication skills. Heinrichs ${ }^{21}$ described a problem-based learning curriculum model and discussed how it had a positive effect on student communication skills with closely supervised learning experiences. To date, no studies have been found in athletic training to determine the opportunities students are given to communicate during their clinical experiences. The purpose of our study was to determine what opportunities students are given during their clinical experiences for professional communication with stakeholders. More specifically, we wanted to learn more about which stakeholders students are talking to and if those opportunities differed based on various characteristics of the education program. We were not trying to measure the quality of the communication, just the opportunity for communication. For the purpose of our project we defined professional communication as directly related to the health care of the athlete/patient and not day-today communication.

\section{METHODS}

An online survey instrument, the Athletic Training Student Communication (ATSC) instrument, was created for this study. To develop this instrument, a convenience sample of students was interviewed to delineate the various stakeholders they professionally communicate with during clinical assignments. The stakeholders identified in this project were derived from discussions with students and preceptors and represent the generalized members of the sports medicine team. Athletic coach/clinic director and athlete/patient are the most obvious stakeholders that a team-based athletic trainer will interact with. Parents, administrators, peers/ colleagues, and other health care professionals are additional members of the sports medicine team as they are all involved in the care of the athlete/patient. A pilot study was conducted to establish content validity and reliability. To establish validity, 4 program directors (PDs) experienced in survey research and clinical supervision and 10 students were sent the ATSC (both as a URL and a hard copy) to review it for clarity and relevance. Minor modifications to the directions and 1 item (athletic affiliation of host institution) were made based on the feedback from the PDs and students. To establish reliability, we used the testretest method with a convenience sample by asking students from 3 athletic training programs (ATPs) to complete the ATSC twice within 1 week. The test-retest data from 52 students were analyzed for consistency by summing each variable from the first administration and comparing that with the second administration. Our data revealed an acceptable agreement percentage ranging from $93.75 \%$ to $100 \%$ for all items.

The ATSC measured 3 sets of independent variables: (1) personal demographics of the student (sex and year in program); (2) demographics of their home institution (institution name, for tracking purposes only; state versus private governance; degree type offered; and athletic affiliation); and (3) demographics of their clinical experience (setting, derived from the National Athletic Trainers' Association membership list; sport assignment[s] when applicable; and athletic affiliation when at a college/ university/junior college). A distinction was made with regards to athletic affiliation of the host institution and clinical assignment because many students are enrolled at one institution but complete assignments at another. The ATSC measured 1 set of dependent variables, the stakeholders with whom participants communicated during the 
prior week (athletic coaches/clinic directors, patients/athletes, parents, administrative personnel, peers/colleagues, other health professionals). Students were asked to indicate which stakeholders they engaged in professional communication with during the prior week of their clinical assignments by selecting a check-box-formatted question.

\section{Participants}

Study participants were students enrolled in ATPs accredited by the Commission on Accreditation of Athletic Training Education. Participants were sent an e-mail message with a URL link to the survey instrument by their respective PD. The PDs for all accredited ATPs were solicited via e-mail, with follow-up phone calls when needed, to ensure participation and to collect program enrollment data. Institutional review was granted by the author's institution and each participant reviewed a consent information statement before completing the ATSC instrument.

\section{Data Collection and Analysis}

Data were captured via Qualtrics (Qualtrics, Inc, Provo, UT) and coded for analysis via SPSS 20.0 (PASW, Inc, Chicago, IL). Basic descriptive statistics were calculated to describe the sample. Our primary research question was to explore the differences in professional communication opportunities with various stakeholders based upon characteristics of the education program and type of clinical experience. To compare 2 categorical variables, we choose to conduct a $\chi^{2}$ analysis. We used a goodness-of-fit analysis to evaluate how likely it was that any observed difference between the variables arose by chance. For our research question, $\chi^{2}$ analyses were conducted between relevant pairs of categorical variables. The $\chi^{2}$ analysis uses a contingency table in which the observed value is compared with a calculated "expected" value to determine significance. Though there were many of these analyses, significance levels were set at .05 for each analysis. Yates ${ }^{22}$ created a correction to prevent overestimation of statistical significance in $2 \times 2$ contingency tables. Sokal and Rohlf ${ }^{23}$ suggest that the Yates correction may tend to overcorrect and may increase a type II error. Because many of our analyses do not fit a simple $2 \times 2 \chi^{2}$ analysis, we chose to use the .05 level.

Because of low numbers of reported cases in many nontraditional settings, we grouped the clinical experience setting variable as emerging practices, secondary school, or college/ university/junior college. With the wide variety of models in length of clinical education from program to program (ranging from 2-year models to 4-year models), we chose to analyze the enrollment year of student based upon novice (first year) versus more experienced (second, third, and fourth years combined). Although this approach lost the actual year the student was enrolled, it allowed for the comparison of students from a variety of clinical education models. To further explore this important variable of year in program, we conducted an analysis based on 2 homogenous groups of students: the 3-year program model $(\mathrm{n}=553 ; 59 \%$ of the sample) and the 2-year program model $(\mathrm{n}=186 ; 20 \%$ of the sample). Although we chose to explore these 2 program models, no direct statistical comparison was made because of the nature of the nonparametric analysis.

\section{RESULTS}

\section{Participants}

Table 1 illustrates the demographics of the 113 (31\% of programs at time of study, February 2013) programs and the students included in the study. Judging by the demographics of our sample in comparison with percentages available in the literature, ${ }^{24}$ we achieved a representative sample with regards to the governance of the institution, the degree type being offered, and the athletic affiliation of the host institution. National Athletic Trainers' Association district distribution was close to representative with the exception of District 5, where the research project originated and participation was higher. We chose not to study the length of the program, as we felt the real indicator of opportunities to communicate was based upon the enrollment status of the student, not the structure of the curriculum. Table 1 illustrates the demographics of the 932 (23\% of those who were solicited by their PD) students (308 male and 624 female) who submitted responses. Here, too, judging from the literature, ${ }^{24}$ we achieved a representative sample with regards to governance of the institution and degree type being offered.

Table 2 illustrates the clinical experience settings reported by the students. The vast majority (72\%) of clinical experiences reportedly occurred in the college/university/junior college setting, which left $20 \%$ in the secondary school setting and the remaining $8 \%$ in the emerging practices setting. Those participants $(\mathrm{n}=77)$ who indicated "Other" were grouped with the closest related sport assignment at the athletic affiliation level of their home institution.

Table 3 illustrates the frequency of participant communication with the various stakeholders. The majority of students' reported communication was with athlete/patient $(\mathrm{n}=851)$ or peers $(\mathrm{n}=827)$. The smallest number of opportunities reported occurred with parents $(n=92)$.

\section{$\chi^{2}$ Analysis}

Table 4 illustrates the significant $\varphi$ and Cramer V correlation values obtained with the $\chi^{2}$ analysis. Interpretations of $\varphi$ and Cramer V correlation values are based upon the distribution of the variables: when the variables are distributed evenly (50/ 50 ) a correlation can range from +1 to -1 . In our study, none of the variables had an even distribution; therefore, the significance of the correlation is more important than the actual value. For interpretation of the correlation values, we used the following scale: 0.01 to 0.19 is small, 0.20 to 0.29 is moderate, $>0.30$ is strong. ${ }^{25}$ The highest occurrence of correlations occurred with the year in program for 3-year program models (6 correlations) and clinical rotation setting (5 correlations) variables. Correlations in athletic affiliation of clinical experience (2 correlations), year in program for 2-year program models (2 correlations), and sex of student (1 correlation) were also found. There were no significant correlations for the athletic affiliation of the home institution, state/private affiliation of home institution, or degree type being offered.

A closer examination of the significant correlations follows and is organized by independent variable. Differences are noted between the observed and expected percentages of communication within each group. 
Table 1. Institution Demographics $(\mathrm{N}=113)$ With National Averages ${ }^{24}$ and Student Demographics $(\mathrm{N}=932)$

\begin{tabular}{|c|c|c|c|c|c|}
\hline \multirow[b]{2}{*}{ Characteristic } & \multicolumn{3}{|c|}{ Institution } & \multicolumn{2}{|c|}{ Student } \\
\hline & Sample No. & Sample \% & National \% & Sample No. & Sample \% \\
\hline \multicolumn{6}{|l|}{ Sex } \\
\hline $\begin{array}{l}\text { Male } \\
\text { Female }\end{array}$ & & & & $\begin{array}{l}308 \\
624\end{array}$ & $\begin{array}{l}33 \\
67\end{array}$ \\
\hline \multicolumn{6}{|l|}{ Year in program } \\
\hline $\begin{array}{l}\text { First } \\
\text { Second } \\
\text { Third } \\
\text { Fourth }\end{array}$ & & & & $\begin{array}{r}406 \\
325 \\
178 \\
23\end{array}$ & $\begin{array}{r}44 \\
35 \\
19 \\
2\end{array}$ \\
\hline \multicolumn{6}{|l|}{ Governance } \\
\hline $\begin{array}{l}\text { Private } \\
\text { State }\end{array}$ & $\begin{array}{l}048 \\
065\end{array}$ & $\begin{array}{l}43 \\
58\end{array}$ & $\begin{array}{l}46 \\
54\end{array}$ & $\begin{array}{l}264 \\
668\end{array}$ & $\begin{array}{l}28 \\
72\end{array}$ \\
\hline \multicolumn{6}{|l|}{ Degree type } \\
\hline $\begin{array}{l}\text { Undergraduate } \\
\text { Master's }\end{array}$ & $\begin{array}{l}103 \\
010\end{array}$ & $\begin{array}{r}92 \\
8\end{array}$ & $\begin{array}{r}93 \\
7\end{array}$ & $\begin{array}{r}854 \\
78\end{array}$ & $\begin{array}{r}92 \\
8\end{array}$ \\
\hline \multicolumn{6}{|l|}{ Athletic affiliation } \\
\hline $\begin{array}{l}\text { NCAA Div } 1 \\
\text { NCAA Div } 2 \\
\text { NCAA Div } 3 \\
\text { NAIA/other }\end{array}$ & $\begin{array}{l}051 \\
027 \\
023 \\
012\end{array}$ & $\begin{array}{l}45 \\
24 \\
20 \\
11\end{array}$ & $\begin{array}{r}40 \\
25 \\
28 \\
7\end{array}$ & $\begin{array}{r}513 \\
169 \\
189 \\
61\end{array}$ & $\begin{array}{r}55 \\
18 \\
20 \\
7\end{array}$ \\
\hline \multicolumn{6}{|l|}{ NATA district } \\
\hline $\begin{array}{r}1 \\
2 \\
3 \\
4 \\
5 \\
6 \\
7 \\
8 \\
9 \\
10\end{array}$ & $\begin{array}{l}006 \\
008 \\
012 \\
021 \\
026 \\
010 \\
006 \\
010 \\
011 \\
002\end{array}$ & $\begin{array}{r}5 \\
7 \\
11 \\
19 \\
23 \\
9 \\
5 \\
9 \\
10 \\
2\end{array}$ & $\begin{array}{r}7 \\
10 \\
14 \\
25 \\
13 \\
7 \\
4 \\
5 \\
12 \\
3\end{array}$ & & \\
\hline
\end{tabular}

Abbreviations: Div, division; NAIA, National Association of Intercollegiate Athletics; NATA, National Athletic Trainers' Association; NCAA, National Collegiate Athletic Association.

\section{Year in Program for 3-Year Program Models}

Year in program for 3-year program models had a small significant correlation for communication with an athletic coach/clinic director (Cramer V $=0.15, P=.000)$. First-year students (33.5\% observed versus $43.6 \%$ expected) reported less communication with an athletic coach/clinic director than second-year (35.0\% observed versus $29.8 \%$ expected) and third-year students ( $31.6 \%$ observed versus $26.6 \%$ expected).

Year in program for 3-year program models had a small significant correlation for communication with an athlete/ patient (Cramer $\mathrm{V}=0.15, P=.002$ ). First-year students (41.2\% observed versus $43.6 \%$ expected) reported less communication with an athlete/patient than second-year (30.9\% observed versus $29.8 \%$ expected) and third-year students (27.9\% observed versus $26.6 \%$ expected).

Year in program for 3-year program models had a small significant correlation for communication with a parent (Cramer $\mathrm{V}=0.16, P=.001)$. First-year students $(22.4 \%$ observed versus $43.6 \%$ expected) reported less communication with a parent than
Table 2. Clinical Rotation Description $(\mathbf{N}=932)$

\begin{tabular}{lrr}
\hline Setting & No. & $\%$ \\
\hline University/college/junior college & & \\
NCAA Div 1 & 334 & 35.8 \\
NCAA Div 2 & 120 & 13.0 \\
NCAA Div 3 & 154 & 16.5 \\
NAIA/Other & 060 & 6.4 \\
High school & 191 & 20.0 \\
Emerging practices & & \\
Clinic/hospital & 044 & 05.0 \\
Health/fitness industry & 003 & 00.3 \\
Industrial/corporate & 000 & 00.0 \\
Military/government/law enforcement & 003 & 00.3 \\
Professional sports/performing arts & 004 & 00.4 \\
Sales/marketing & 000 & 00.0 \\
Youth sports/intramural & 002 & 00.2 \\
Other & 017 & 02.0 \\
\hline
\end{tabular}

Abbreviations: Div, Division; NAIA, National Association of Intercollegiate Athletics; NCAA, National Collegiate Athletic Association. 
Table 3. Frequency of Participant Communication with Stakeholders

\begin{tabular}{lc}
\hline Stakeholder & Frequency \\
\hline Coach/director & 468 \\
Athlete/patient & 851 \\
Parent & 92 \\
Administrator & 200 \\
Peer/colleague & 827 \\
Other health care professional & 263 \\
\hline
\end{tabular}

second-year (30.6\% observed versus $29.8 \%$ expected) and thirdyear students ( $46.9 \%$ observed versus $26.6 \%$ expected).

Year in program for 3-year program models had a small significant correlation for communication with an administrator (Cramer $\mathrm{V}=0.15, P=.002)$. First-year students $(28.9 \%$ observed versus $43.6 \%$ expected) reported less communication with an administrator than second-year $(36.8 \%$ observed versus $29.8 \%$ expected) and third-year students (34.2\% observed versus $26.6 \%$ expected).

Year in program for 3-year program models had a small significant correlation for communication with a peer/ colleague (Cramer $\mathrm{V}=0.13, P=.007$ ). First-year students $(41.3 \%$ observed versus $43.6 \%$ expected) reported less communication with a peer/colleague than second-year (31.0\% observed versus $29.8 \%$ expected) and third-year students $(27.6 \%$ observed versus $26.6 \%$ expected).

Year in program for 3-year program models had a small significant correlation for communication with other health care professionals (Cramer $\mathrm{V}=0.19, P=.000$ ). First-year students (29.0\% observed versus $43.6 \%$ expected) reported less communication with other health care professionals than second-year (31.7\% observed versus $29.8 \%$ expected) and third-year students (39.3\% observed versus $26.6 \%$ expected).

\section{Clinical Experience Setting}

Clinical experience setting (defined as college/university/junior college, secondary school, and emerging practices) had a small significant correlation with communication with an athletic coach/clinic director (Cramer $\mathrm{V}=0.14, P=.000$ ). Students engaged in secondary school clinical experiences $(26.1 \%$ observed versus $20.5 \%$ expected) reported more communication with an athletic coach/clinic director than those in other settings (emerging practices $=7.3 \%$ observed versus $7.8 \%$ expected; university $/$ college $/$ junior college $=66.7 \%$ observed versus $71.1 \%$ expected).

Clinical experience setting had a strong significant correlation with communication with a parent (Cramer $\mathrm{V}=0.42, P=$ .000). Students engaged in secondary school and emerging practices clinical experiences (secondary school $=67.4 \%$ observed versus $20.5 \%$ expected; emerging practices $=16.3 \%$ observed versus $7.8 \%$ expected) reported more communication with a parent than students engaged in college/university/ junior college clinical experiences $(16.3 \%$ observed versus $71.7 \%$ expected).

Clinical experience setting had a small significant correlation with communication with an administrator (Cramer $\mathrm{V}=0.17$, $P=.000$ ). Students engaged in emerging practices and college/ university/junior college clinical experiences (emerging practices $=16.3 \%$ observed versus $7.8 \%$ expected; college/ university/junior college $=57.5 \%$ observed versus $71.7 \%$ expected) reported less communication with an administrator than students engaged in secondary school clinical experiences (13.5\% observed versus $7.8 \%$ expected).

Clinical experience setting had a small significant correlation with communication with a peer/colleague (Cramer $\mathrm{V}=0.09$, $P=.027)$. Students engaged in emerging practices and secondary school clinical experiences (emerging practices $=$ $7.3 \%$ observed versus $7.8 \%$ expected; secondary school $=$ $19.7 \%$ observed versus $20.5 \%$ expected) reported less communication with a peer/colleague than students engaged in college/university/junior college clinical experiences $(73.0 \%$ observed versus $71.7 \%$ expected).

Clinical experience setting had a small significant correlation with communication with other health care professionals (Cramer $\mathrm{V}=0.15, P=.000)$. Students engaged in emerging practices ( $14.1 \%$ observed versus $7.8 \%$ expected) and second-

Table 4. Significant $\varphi$ and Cramer V Correlations ${ }^{a}$

\begin{tabular}{|c|c|c|c|c|c|c|}
\hline \multirow[b]{2}{*}{ Independent Variables } & \multicolumn{6}{|c|}{ Dependent Variables } \\
\hline & $\begin{array}{l}\text { Coach/ } \\
\text { Director }\end{array}$ & $\begin{array}{l}\text { Athlete/ } \\
\text { Patient }\end{array}$ & Parent & Administrator & $\begin{array}{c}\text { Peer/ } \\
\text { Colleague }\end{array}$ & $\begin{array}{c}\text { Other Health } \\
\text { Care Prof }\end{array}$ \\
\hline $\begin{array}{l}\text { Sex of student } \\
\text { Athletic affiliation of home institution } \\
\text { State/Private affiliation of home institution } \\
\text { Degree type being offered } \\
\text { Year in program for 2-year program models } \\
\text { Year in program for 3-year program models } \\
\text { Clinical experience setting } \\
\text { Athletic affiliation of clinical experience }\end{array}$ & $\begin{array}{l}-0.011 \\
-0.022 \\
-0.045 \\
-0.053 \\
-0.005 \\
-0.197^{* *} \\
-0.143^{* *} \\
-0.119\end{array}$ & $\begin{array}{l}-0.018 \\
-0.057 \\
-0.000 \\
-0.003 \\
-0.148^{*} \\
-0.149^{\star *} \\
-0.069 \\
-0.067\end{array}$ & $\begin{array}{l}-0.005 \\
-0.107 \\
-0.008 \\
-0.030 \\
-0.121 \\
-0.159^{* *} \\
-0.418^{* *} \\
-0.143^{* *}\end{array}$ & $\begin{array}{l}-0.006 \\
-0.082 \\
-0.033 \\
-0.050 \\
-0.024 \\
-0.147^{* *} \\
-0.169^{* *} \\
-0.121^{*}\end{array}$ & $\begin{array}{l}-0.012 \\
-0.063 \\
-0.017 \\
-0.027 \\
-0.042 \\
-0.130^{* *} \\
-0.088^{*} \\
-0.103\end{array}$ & $\begin{array}{l}-0.071^{*} \\
-0.064 \\
-0.003 \\
-0.043 \\
-0.160^{*} \\
-0.199^{* *} \\
-0.153^{* *} \\
-0.080\end{array}$ \\
\hline
\end{tabular}

Abbreviation: Prof, professional.

${ }^{a} \varphi$ values were used for $2 \times 2$ contingency analysis; Cramer $V$ values were used for all contingency analyses other than $2 \times 2$.

* Indicates a significant correlation between variables at $P \leq .05$.

** Indicates a significant correlation between variables at $P \leq .01$. 
ary school $(22.1 \%$ observed versus $20.5 \%$ expected $)$ clinical experiences reported more communication with other health care professionals than students engaged in college/university/ junior college clinical experiences $(63.9 \%$ observed versus $71.7 \%$ expected).

\section{Year in Program for 2-Year Program Models}

Year in program for 2-year program models had a small significant correlation for communication with an athlete/ patient (Cramer $\mathrm{V}=0.15, P=.04)$. First-year students $(50.9 \%$ observed versus $53.2 \%$ expected) reported less communication with an athlete/patient than second-year students $(49.1 \%$ observed versus $46.8 \%$ expected).

Year in program for 2-year program models had a small significant correlation for communication with other health care professionals (Cramer $\mathrm{V}=0.16, P=.029)$. First-year students (41.9\% observed versus $53.2 \%$ expected) reported less communication with other health care professionals than second-year students ( $58.1 \%$ observed versus $46.8 \%$ expected).

\section{Athletic Affiliation}

Athletic affiliation of the collegiate clinical experience had a small significant correlation with communication with a parent (Cramer $\mathrm{V}=0.14, P=.009$ ). Students engaged in clinical experiences at the National Collegiate Athletic Association (NCAA) Division I and National Association of Intercollegiate Athletics (NAIA) levels (NCAA Division I = $13.3 \%$ observed versus $50.0 \%$ expected; NAIA $=0 \%$ observed versus $6.9 \%$ expected) reported less communication with parents than students engaged in clinical experiences at the NCAA Division II and III levels (NCAA Division II $=33.3 \%$ observed versus $18.0 \%$ expected; NCAA Division III $=53.3 \%$ observed versus $23.1 \%$ expected).

Athletic affiliation of the collegiate clinical experience had a small significant correlation with communication with an administrator (Cramer $\mathrm{V}=0.12, P=.044)$. Students engaged in clinical experiences at the NCAA Division I and III levels (NCAA Division $\mathrm{I}=42.6 \%$ observed versus $50.0 \%$ expected; Division III $=20.0 \%$ observed versus $23.1 \%$ expected) reported less communication with an administrator than students engaged in clinical experiences at the NCAA Division II and NAIA levels (NCAA Division II $=27.8 \%$ observed versus $18.0 \%$ expected; NAIA $=7.0 \%$ observed versus $6.9 \%$ expected).

\section{Sex}

Sex had a small significant negative correlation with communication with other health care professionals $(\varphi=$ $-0.07, P=.029)$. Male students (38.4\% observed versus $33.0 \%$ expected) reported more communication with other health care professionals than female students $(61.6 \%$ observed versus $67.0 \%$ expected).

\section{DISCUSSION}

Our results suggest that the year in program and clinical experience setting are the most significant indicators of student communication opportunities. Although there were a few significant correlations outside of those independent variables, they could be considered outliers, with only 1 significant correlation across the dependent variables (year in program for 2-year program models correlated with athlete/ patient and other health care professionals, sex of student correlated with other health care professionals, and athletic affiliation of clinical experience correlated with parent and administrator).

One of our primary findings is that year in program for 3-year program models had significant correlations with all dependent variables, whereas year in program for 2-year program models only had 2 significant correlations. Not surprisingly, this would indicate that 3-year program models provide students with more opportunities to communicate than 2-year program models. With the continuing debate within the profession regarding the professional level degree move to a graduate level, the length of the program can have a significant impact on students' opportunities for communication.

The sample obtained was representative of education programs for several factors (state versus private affiliation, bachelor's versus master's degree, and athletic affiliation) and thus the conclusions may be generalized to other programs based upon those factors. A response rate of $31 \%$ of the accredited programs at the time of this study is good for survey-based research. ${ }^{26}$ The sample indicates that $72 \%$ of students are engaged in clinical rotations at the university/ college/junior college setting and that many students are engaged in Division I rotations. The data also indicated that students reported more opportunities to communicate at lower levels of athletic affiliation. This is an important consideration for program faculty when determining the mix of clinical experiences students will gain during their education. Perhaps more emphasis needs to be placed on lower levels of athletic affiliation to give students more opportunities to practice their communication skills.

A preceptor-led debriefing provides an opportunity for the student to ask questions and learn appropriate communication skills through observation, scaffolding, and clinical feedback. Communication and feedback from preceptors has been found to increase skills, ${ }^{27}$ confidence, ${ }^{28}$ knowledge, ${ }^{27,28}$ self-esteem, ${ }^{28}$ productivity, ${ }^{28}$ clinical performance, ${ }^{28,29}$ and professional behavior. ${ }^{28}$ Program administrators should encourage and promote this interaction to improve the professional communication skills of their students.

Numerous studies have indicated that communication between the clinician and the stakeholder impacts the quality of care. ${ }^{6-9}$ One could argue that the quality of the interaction between the athletic trainer and any of these stakeholders will have an impact of the quality of care offered the athlete/ patient. For the practicing athletic trainer to exhibit effective communication skills, they must be practiced and honed as a student with a clinical preceptor present to mentor and model effective communication skills. ${ }^{4}$

Although we have not found any studies that explore the opportunities students have to communicate while engaged in clinical experiences, anecdotal evidence of discussions with colleagues at Division I universities exists warranting further empirical investigations. This anecdotal evidence suggests students in clinical rotations at NCAA Division I athletic 
universities have less access to coaches and administrators, thus fewer opportunities. Coaches and administrators at these universities desire direct communication with the certified athletic trainers as opposed to a student. Parents are often more involved in the health care of their children at the secondary school level with more direct communication with the athletic trainer because of the minor status of the patient.

It is a logical expectation that as students gain experience they would report more opportunities to communicate. However, several variables that were not studied must be considered. The age and emotional intelligence (EI) of the student could have a significant impact on their opportunities to communicate. Wilson et a ${ }^{30}$ studied EI among critical care fellows and residents and found that higher EI scores were correlated with higher communication skills. Students with higher EI may report more opportunities to communicate.

When making clinical assignments, program administrators need to consider a myriad of variables that will affect the eventual outcome of that experience. Among those variables are the amount of previous experience and the clinical setting. If programs wish to enhance students' opportunities to communicate, they should consider placing students in settings where those opportunities are more likely to present themselves and time those experiences with academic year in the program. Based on our data, a first-year student is less likely to communicate wherever the student is placed when compared with a second- or third-year student. Program administrators should consider the findings of this study when determining the mixture of clinical assignments for a given student over the course of the student's education.

Outside of accreditation requirements, students will have more opportunities for communication at lower levels of university/college athletics. There is evidence to suggest that communication training can increase satisfaction with the clinician-patient interaction. ${ }^{13,14}$ Communication training in the clinical setting cannot happen when no authentic opportunities are presented during clinical experiences. Efforts should be made by all education programs to incorporate communication, both didactically and clinically. Zick et $\mathrm{al}^{31}$ conducted a study in which first-year medical students assessed their own communication skills by reviewing a video of their interaction with a simulated patient. Zick et $\mathrm{al}^{31}$ found that the self-assessment process forced students to attend to tasks and skills relevant to effective communication. Program administrators should consider simulated patients not only as an avenue to enhancing clinical skills such as patient care, but also as a way to enhance soft skills such as communication.

Our project has highlighted several interesting findings related to opportunities for student communication. However, a few limitations must be considered when determining the applicability of our findings. Our study sample, although large, was a recruited sample of convenience. This convenience was further compounded by the students' voluntary ability to participate; thus, we cannot say that our findings represent the opportunities to communicate afforded to all students. One of our major findings of year in the program as a significant indicator was limited by the multiple curriculum models exhibited in the education programs. To compare an undergraduate student with a graduate student is not accurate and to compare a second-year undergraduate student with a second-year graduate student is equally tenuous. Future studies should consider the age of the student as a possible indicator of communication opportunities.

Our study did not attempt to control for what course work the students had completed before their clinical experiences. It is possible that some curriculum models require a communications course, and this could influence the students' willingness and ability to engage in professional communication. Our study did not control for the number of students at a given clinical rotation. More students at a given clinical rotation may decrease the number of opportunities for communication with various stakeholders. Future studies could include this variable for consideration.

Our data collection was based upon the recall of the student for the previous week of clinical experiences. Recall methods can introduce error when compared with immediate recording. Finally, this study focused on opportunity to communicate and not quality of communication. Although more opportunities could be viewed as a strength, the quality of those interactions needs to be considered and was not addressed in this study. An exploration of opportunities and perceived competency among students in different types of programs would be of value to the profession.

\section{CONCLUSIONS}

Based on our data, the following conclusions may be drawn with consideration to the expressed limitations: (1) as students matriculate through the program and gain experience, they report more opportunities to communicate with a wide variety of stakeholders, and (2) the setting in which students gain clinical experience is very important to the reported opportunities to communicate. Students engaged in secondary school and midlevel collegiate settings have more opportunities for communication with a variety of stakeholders. Programs should encourage preceptors to involve students in professional communication with stakeholders at a level appropriate to the students' education and experience. Various strategies can be developed specific to a given setting that could allow for more communication opportunities.

\section{REFERENCES}

1. Carr W, Volberding J. Employer and employee opinions of thematic deficiencies in new athletic training graduates. Athl Train Educ J. 2012;7(2):53-59.

2. Massie J, Strang A, Ward R. Employer perceptions of the academic preparation of entry-level certified athletic trainers. Athl Train Educ J. 2009;4(2):70-74.

3. Burke M. Communication skills training. Paper presented at: American Personnel and Guidance Convention; April 11-16, 1973; St Louis, MO.

4. Ericsson K, Krampe R, Tesch-Römer C. The role of deliberate practice in the acquisition of expert performance. Psychol Rev. 1993;100(3):363.

5. Ericsson KA. Deliberate practice and acquisition of expert performance: a general overview. Acad Emerg Med. 2008;15(11): 988-994. 
6. Epstein R, Street R. Patient-Centered Communication in Cancer Care: Promoting Healing and Reducing Suffering. NIH Publication No. 07-6225. Bethesda, MD: National Cancer Institute, US Department of Health and Human Services, National Institutes of Health; 2007.

7. Arora N. Interacting with cancer patients: the significance of physicians' communication behavior. Soc Sci Med. 2003;57(5): 791-806.

8. Kaplan S, Greenfield S, Ware J Jr. Assessing the effects of physician-patient interactions on the outcomes of chronic disease. Med Care. 1989;27(3):S110.

9. Oates J, Weston W, Jordan J. The impact of patient-centered care on outcomes. Fam Pract. 2000;49:796-804.

10. Hickson G, Clayton E, Entman S, et al. Obstetricians' prior malpractice experience and patients' satisfaction with care. JAMA. 1994;272(20):1583-1587.

11. Stewart M. Effective physician-patient communication and health outcomes: a review. CMAJ. 1995;152(9):1423-1433.

12. Levinson W, Lesser CS, Epstein RM. Developing physician communication skills for patient-centered care. Health Aff (Millwood). 2010;29(7):1310-1318.

13. Stein T, Kwan J. Thriving in a busy practice: physician-patient communication training. Eff Clin Pract. 1999;2(2):63-70.

14. Brown J, Boles M, Mullooly J, Levinson W. Effect of clinician communication skills training on patient satisfaction a randomized, controlled trial. Ann Intern Med. 1999;131(11):822-829.

15. Moulton MA, Molstad S, Turner A. The role of athletic trainers in counseling collegiate athletes. J Athl Train. 1997;32(2):148150 .

16. Wiese D, Weiss M, Yukelson D. Sport psychology in the training room: a survey of athletic trainers. Sport Psychol. 1991;5(1):1524.

17. Hamson-Utley JJ, Martin S, Walters J. Athletic trainers' and physical therapists' perceptions of the effectiveness of psychological skills within sport injury rehabilitation programs. $J$ Athl Train. 2008;43(3):258-264.

18. Laurent T, Weidner TG. Clinical instructors' and student athletic trainers' perceptions of helpful clinical instructor characteristics. $J$ Athl Train. 2001;36(1):58-61.

19. Weidner TG, Henning JM. Development of standards and criteria for the selection, training, and evaluation of athletic training approved clinical instructors. J Athl Train. 2004;39(4): 335-343.
20. Weidner T, Henning J. Importance and applicability of approved clinical instructor standards and criteria to certified athletic trainers in different clinical education settings. $J$ Athl Train. 2005;40(4):326-332.

21. Heinrichs K. Problem-based learning in entry-level athletic training professional-education programs: a model for developing critical-thinking and decision-making skills. J Athl Train. 2002;37(4 suppl):S-189.

22. Yates F. Contingency tables involving small numbers and the $\chi^{2}$ test. Suppl J R Stat Soc. 1934;1(2):217-235.

23. Sokal R, Rohlf F. Biometry: The Principles and Practice of Statistics in Biological Research. 2nd ed. New York, NY: WH Freeman and Co; 1981.

24. Carr W, Volberding J. Sampling methods and the accredited population in athletic training education research. Athl Train Educ J. 2009;4(2):75-81.

25. Frey B. Statistics Hacks: Tips \& Tools for Measuring the World and Beating the Odds. Sebastopol, CA: O'Reilly Media, Inc; 2008.

26. Carley-Baxter L, Hill C, Roe D, Twiddy S, Baxter R, Ruppenkamp J. Does response rate matter? Journal editors use of survey quality measures in manuscript publication decisions. Surv Pract. 2009;2(7). http://www.surveypractice.org/index.php/ SurveyPractice/article/view/192/html. Accessed January 20, 2016.

27. Barnum M, Guyer M, Levy L, et al. Questioning and feedback in athletic training clinical education. Athl Train Educ J. 2009;4(1): 23-27.

28. Glover P. "Feedback. I listened, reflected and utilized": third year nursing students' perceptions and use of feedback in the clinical setting. Int J Nurs Pract. 2000;6(5):247-252.

29. Boehler M, Rogers D, Schwind C, et al. An investigation of medical student reactions to feedback: a randomised controlled trial. Med Educ. 2006;40(8):746-749.

30. Wilson M, Gajic O, Benzo R, De Moraes A. The impact of emotional intelligence on burnout, job satisfaction, self-compassion, and communication skills in critical care trainees. Am J Respir Crit Care Med. 2015;191:A2228.

31. Zick A, Granieri M, Makoul G. First-year medical students' assessment of their own communication skills: a video-based, open-ended approach. Patient Educ Couns. 2007;68(2):161166. 